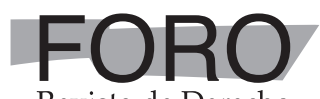

Revista de Derecho

\title{
El matrimonio civil igualitario como forma de ejercer el derecho a la igualdad y no discriminación
}

Equal civil marriage as a way of secure the equal right and non discrimination

\section{María Inés Orellana Ramírez}

Abogada, Ecuador

marines_orellana22@hotmail.com

ORCID: 0000-0002-9528-2201

DOI: https://doi.org/10.32719/26312484.2019.32.6

Fecha de recepción: 30 de abril de 2019

Fecha de aceptación: 9 de septiembre de 2019 


\section{RESUMEN}

Una pareja homosexual basada en la Opinión Consultiva OC-24/17, busca contraer matrimonio civil. La petición es negada en virtud de varias razones, por lo que se interpone una acción de protección. En primera instancia se acepta la demanda, mientras que en el superior se declara sin lugar a la misma. Es aquí que se debe considerar si se vulnera o no el derecho a la igualdad y no discriminación y no únicamente de los peticionarios, sino, en general, de las personas con una distinta orientación sexual, categoría protegida por la actual Constitución ecuatoriana, además de determinar si el mencionado instrumento internacional forma parte del bloque de constitucionalidad, ya que de ser afirmativo sería parte del ordenamiento vigente $y$, por lo tanto, de obligatorio cumplimiento.

Adicionalmente, se realiza un análisis si en realidad se está cumpliendo el principio de igualdad y no discriminación en razón de la orientación sexual.

Palabras Clave: Matrimonio, igualitario, opinión consultiva, no discriminación.

\section{ABSTRACT}

A homosexual couple based on Advisory Opinion OC-24/17, want to celebrate between them civil marriage. Petition denied due to several reasons, as such, they present a protection action. In first instance the demand is accepted, while the superior judge not accept the petition. This is where we must consider whether or not the right to equality and non-discrimination is violated and not only of the petitioners but in general to people with a different sexual orientation, a category protected by the current Ecuadorian Constitution. In addition to determining if the aforementioned international instrument is part of the constitutionality block since, if it were affirmative, it would be part of the current legislation and, therefore, of mandatory compliance.

Doing an analysis if in reality the right of equality and non discrimination is being fullfilled in reason of sexual orientation.

KEYWORD: Marriage, equality, advisory opinión, non discrimination.

\section{INTRODUCCIÓN}

$\mathrm{E}$ 1 matrimonio civil es una institución vigente dentro del ordenamiento jurídico ecuatoriano. La actual Constitución ecuatoriana determinó en el art. 67 que debe celebrarse únicamente entre hombre y mujer; de igual manera se estableció que todas las personas gozan del derecho a la igualdad y nadie puede ser discriminado por varias categorías, una de ellas, la orientación sexual. Años atrás, se estatuyó que las parejas 
homosexuales podían inscribir una unión de hecho al cumplir ciertos requisitos y con esto se garantizaban de mejor manera sus derechos.

Con la Opinión Consultiva 24/17 y la aplicación del mismo en la sentencia número 184-18-SEP-CC, del proceso de Satya, varias parejas homosexuales han buscado contraer matrimonio civil en virtud de la normativa constitucional, al considerar que dicho instrumento formaría parte del bloque de constitucionalidad y por ende aplicable de forma directa e inmediata. Adicionalmente, asegurando que como seres humanos se tiene derecho a formar una familia, y no ser discriminados ni tratados de manera distinta al resto de personas, en tal razón, no existiría justificación válida para prohibir la celebración del matrimonio civil en parejas del mismo sexo.

Es importante estudiar esta institución no de una manera formal y legalista, sino desde una óptica constitucional, pro ser humano y en relación directa con la protección de derechos. Desde un punto de vista académico este tema es relevante en razón de que se deberá determinar si se viola el derecho a la igualdad y no discriminación de las personas homosexuales al no permitirles contraer matrimonio civil; y realizar un estudio sobre la Opinión Consultiva 17/24 con fecha noviembre de 2017, como vinculante o no para el Estado ecuatoriano.

Para la elaboración de este ensayo se ha tomado como referencia un proceso de acción de protección con número 01204-2018-03635, interpuesta en la ciudad de Cuenca, provincia del Azuay, por una pareja homosexual en razón de la negativa por parte de servidores y autoridades del Registro Civil a la celebración del matrimonio civil; se realizará un análisis de textos para poder llegar a las finalidades mencionadas en párrafos anteriores.

\section{ANÁLISIS Y RESULTADOS}

\section{Antecedentes: CAso AzuAY}

En la ciudad de Cuenca, provincia del Azuay, ante la Unidad Judicial de la Mujer, Niñez y Adolescencia, se presenta una acción de protección. Los actores son una pareja homosexual que acudió al Registro Civil en compañía de dos testigos, con el objetivo de contraer matrimonio civil en virtud de la Opinión Consultiva OC-24/17 del 24 de noviembre de 2017.

El Registro Civil indicó que no podían proceder a esta celebración, ya que el mismo es específicamente entre hombre y mujer. Al indicarle que, mediante un instrumento internacional, se encontraban facultados para aquello, afirmaron que no se han determinado los procedimientos internos para este tipo de contrato y, a manera de solución, ofrecieron inscribir la unión de hecho de los comparecientes. Los peticiona- 
rios solicitan al coordinador zonal 6 se oficie disponiendo dicho matrimonio, petición que fue negada por la autoridad. En razón de esto, interponen la mencionada garantía jurisdiccional.

La vulneración que alegan es: la no aplicación directa e inmediata de los derechos consagrados en la Constitución y en tratados internacionales; derecho a la igualdad y no discriminación y principio de seguridad jurídica.

El Registro Civil señala que no se han vulnerado los derechos de los peticionarios, en razón de que como institución deben aplicar lo que se encuentra establecido en la Constitución y en la ley. El art. 67 explícitamente determina que el matrimonio es la unión entre hombre y mujer; por ende, no pueden celebrar este tipo de actos entre parejas homosexuales tomando como base la opinión consultiva OC-24/17.

El delegado de la Procuraduría General del Estado en Cuenca indica que no se vulneró derecho alguno de los peticionarios; el matrimonio es entre hombre y mujer, por lo que no se podría aplicar la opinión consultiva como en el caso Satya en virtud de que en ese proceso existía un vacío legal, cuestión que en el presente expediente no sucede; mientras que, en este proceso, existe una prohibición expresa en la Constitución ecuatoriana.

En primera instancia, la jueza, acepta la demanda, y ordena que el Registro Civil, oficie el matrimonio entre los peticionarios, disculpas públicas y capacitaciones a los servidores de esta institución para posteriores casos. Esta sentencia fue apelada recayendo en la Sala de lo Laboral de la Corte Provincial del Azuay, tribunal, que negó la acción.

\section{EL MATRIMONIO IGUALITARIO COMO UNA FORMA DE EJERCER}

EL PRINCIPIO DE IGUALDAD Y NO DISCRIMINACIÓN: ANÁLISIS SOCIO JURÍDICO DE LA SENTENCIA

Es parte de la motivación del tribunal que no se ha violentado derecho alguno, ya que a ninguna otra pareja homosexual se le ha permitido contraer matrimonio civil. En caso de que, por razones injustificadas, no se hubiera inscrito la unión de hecho (si lo hubieran solicitado los peticionarios), se configuraría efectivamente la violación a la igualdad y no discriminación, afirmando lo siguiente:

Con propiedad consideramos que la discriminación alegada por los recurrentes, deberían fundase en hechos que prueben que la autoridad del Registro Civil ha otorgado a otras personas, del mismo sexo, en condiciones iguales, la autorización matrimonial, que a ellos no se les ha concedido, por su orientación sexual. No han demostrado la configuración de la discriminación que signifique un atentado contra su dignidad humana y tenga por objeto anular o menoscabar sus derechos y libertades personales [...] La negativa no está encami- 
nada a vulnerar derechos, ni a producir actos discriminatorios, se sustenta en un régimen constitucional y legal. ${ }^{1}$

Se determina adicionalmente, que los actores no han probado efectivamente que se vulneró este derecho por parte de la entidad estatal: "No se ha justificado por ellos que se haya menoscabado o anulado el reconocimiento, goce o ejercicio de los derechos". 2

El punto mencionado es esencial en el presente análisis, ya que, como se determina, no existe una vulneración de derechos constitucionales, en razón de que no ha existido otro caso similar anterior que haya celebrado un matrimonio civil entre parejas homosexuales y, a manera de solución, señalan la unión de hecho, acto que se considera regresivo de derechos y más en razón de ser inherentes a un ser humano.

Si cualquier individuo leyera el anterior razonamiento, pudiera llegar a una conclusión en la que efectivamente no se están violentando derechos constitucionales y, peor aún, humanos, de los comparecientes, sino también de todas las personas que podamos en algún punto ser discriminadas por cualquier razón o categoría protegida.

Roberto Saba indicaba un caso imaginario que resumiré muy brevemente. En un lugar hipotético, las únicas personas que tenían derecho a acceder a la universidad eran los hombres con estudios secundarios terminados. Una mujer interpuso una acción de inconstitucionalidad, en contra del sistema educativo de ese Estado, solicitando se declare inconstitucional dicha norma, se amplíe el derecho y se tenga en cuenta también a las mujeres y como sola condición se establezca haber culminado sus estudios secundarios. En este caso, la corte indicó que no existía discriminación en contra de esta mujer en particular y de las mujeres en general, en virtud de que a ninguna otra mujer o grupo de mujeres se les había permitido ingresar a la universidad pública, y que existiría discriminación si a una sola mujer con anterioridad se le habría concedido esta facultad. ${ }^{3}$ ¿Se podría considerar esto justicia? ¿Podríamos decir que en realidad no existe una discriminación injustificada en contra de, este caso específico, las mujeres?

Para que un Estado cualquiera realice una distinción entre sus miembros, deben ocurrir circunstancias razonables y justificadas, tal y como lo indica Saba: "el Estado puede tratar de modo diferente a las personas siempre y cuando lo haga en forma ho-

1. Función Judicial, Sala de lo Laboral de la Corte Provincial del Azuay, Proceso n. ${ }^{\circ}$ 01204-2018-03635, 2018.

2. Función Judicial, Sala de lo Laboral de la Corte Provincial del Azuay, Proceso n. ${ }^{\circ}$ 01204-2018-03635, 2018.

3. Roberto Saba, Más allá de la igualdad formal ante la ley: ¿qué les debe el Estado a los grupos desventajados? (Buenos Aires: Siglo XXI, 2006), 39-40. 
mogénea, uniforme, y no arbitraria". ${ }^{4}$ Se podría deducir que la decisión de esta corte del caso hipotético no fue justa, ya que no existía ninguna causa para que pueda emplearse distinción alguna y vulneraba indudablemente el derecho a la igualdad y a una vida digna. Ahora, cuando la pregunta es si este pronunciamiento se realizó conforme a la Constitución y a la ley, nuestra respuesta sería afirmativa, en razón de que en la norma se establecía que la educación superior pública era únicamente para hombres que tenían culminados sus estudios secundarios.

Ahora bien, de acuerdo a la Corte Interamericana de Derechos Humanos:

La noción de igualdad se desprende directamente de la unidad de naturaleza del género humano y es inseparable de la dignidad esencial de la persona, frente a la cual es incompatible toda situación que, por considerar superior aún determinado grupo, conduzca a tratarlo con privilegio; o que a la inversa, por considerarlo inferior, lo trate con hostilidad o de cualquier forma lo discrimine del goce de derechos que sí se reconocen a quienes no se consideran incursos en tal situación de inferioridad.

El principio de igualdad y no discriminación posee un carácter fundamental para la salvaguardia de los derechos humanos tanto en el derecho internacional como en el interno. Por consiguiente, los Estados tienen la obligación de no introducir en su ordenamiento jurídico regulaciones discriminatorias, de eliminar de dicho ordenamiento de carácter discriminatorio y de combatir las prácticas discriminatorias. ${ }^{5}$

Aplicando esto a nuestro caso en particular, esta pareja homosexual goza efectivamente del derecho a la igualdad y no discriminación; teóricamente es así, la actual norma suprema, artículo 11 número 2 , expresamente determina este principio, es más, una de las categorías protegidas es la orientación sexual. Pero, si revisamos el artículo 67 del mismo cuerpo normativo, se indica que el matrimonio únicamente será entre hombre y mujer; norma que a priori es discriminatoria, ya que no existe fundamentación razonable, objetiva y no arbitraria para no permitir que una pareja homosexual contraiga matrimonio civil. Al ser el Ecuador parte de la Organización de Estados Americanos y signatario de la Convención Americana sobre Derechos Humanos es nuestra responsabilidad eliminar de nuestro organismo cualquier norma de carácter discriminatorio que, en este caso, sería el inciso segundo del mencionado artículo.

Sin embargo, en un análisis de hecho, podemos concluir que esto está muy lejos de la realidad, específicamente, en este caso, la desigualdad y la discriminación del que son objeto palpable, y se da lo que es un sistema de sometimiento de estos seres

4. Ibíd., 38.

5. Corte Interamericana de Derechos Humanos, Cuadernillo de Jurisprudencia de la Corte, n. ${ }^{\circ}$ 14: Igualdad y No Discriminación, 2017, 4. 
humanos por las creencias, sean religiosas, morales, o de cualquier otra índole, que puedan tener otros (operadores de justicia, fiscales, abogados, público en general).

Se dice muy claramente que no se ha configurado discriminación alguna, en razón de que "ninguna otra pareja homosexual puede o pudo contraer matrimonio con anterioridad"; 6 revisando el ejemplo de Saba, sería como decirle a una mujer que no se le está vulnerando el derecho a la igualdad y no discriminación, a la educación, y como consecuencia a una vida digna, en virtud de que a ninguna otra se le ha concedido la facultad de acceder a la universidad pública. Esto sin lugar a dudas hace que todo el sistema de derechos, y en sí la Constitución progresista, retroceda cincuenta años en el tiempo y volvamos a lo que conocemos como igualdad formal, que Saba conceptualizaba como "la igualdad de trato ante la ley implica la obligación del Estado de tratar igual a aquellas personas que se encuentran en igualdad de circunstancias. Es el derecho que tienen las personas a que no se establezcan excepciones o privilegios que excluyan a unos de los que en iguales circunstancias se concede a otros". ${ }^{7}$

Un Estado puede hacer ciertas distinciones y otorgar ciertos beneficios, con el fin de llegar a una igualdad material. Sobre esto Saba, afirma:

El Estado tiene la facultad constitucional de tratar a las personas de modo diferente, siempre y cuando se funde sobre un criterio justificado [...] La clasificación debe ser razonable, sobre una relación justa y sustancial, de tal modo que todas las personas que se encuentren en iguales circunstancias sean tratadas del mismo modo. ${ }^{8}$

La sentencia n. ${ }^{\circ} 10-18-\mathrm{CN} / 19$ sobre el matrimonio entre personas del mismo sexo, emitida por la actual Corte Constitucional ecuatoriana acerca de la igualdad y no discriminación, prescribe:

La norma legal cuestionada (que priva a las parejas del mismo sexo del poder jurídico de contraer matrimonio), es sospechosa de ser discriminatoria, ya que introduce una diferenciación basada en la "orientación sexual" de las personas, uno de los supuestos en que el artículo 11.7 de la Constitución expresamente prohíbe a prima facie el trato diferenciado. Y esta sospecha de discriminación hace que la norma legal cuestionada sea inconstitucional a menos que logre pasar un testo de igualdad que no es sino una aplicación del principio de proporcionalidad que consista en un escrutinio estricto de constitucionalidad de la ley. Lo que sería imposible, pues no pasaría ni la primera fase del testo, dado que, sobre la base de las consideraciones hechas en párr. 46 supra, no existe un fin constitucional, ni explícito ni

6, Función Judicial, Sala de lo Laboral de la Corte Provincial del Azuay, Proceso n. ${ }^{\circ}$ 01204-2018-03635, 2018.

7. Saba, Más allá de la igualdad formal ante la ley: ¿qué les debe el Estado a los grupos desventajados?, 36.

8. Ibíd., 36-7. 
implícito, que pueda invocarse para la privación del derecho de las parejas del mismo sexo a casarse. Con lo cual, el test concluiría ahí mismo. ${ }^{9}$

Aplicando estos conceptos al análisis, podemos deducir muy claramente que estos grupos, como los LGBTI, han sido vulnerados a lo largo del tiempo. Recordemos que hasta hace más de quince años era un delito ser homosexual. María Lugones en Pureza, impureza y separación manifiesta que la sociedad y los gobernantes buscan que los miembros de esta comunidad sean homogéneos, es decir, iguales en su comportamiento, ideología, costumbres y más, para que de esa forma se pueda ejercer un control y una opresión más efectiva de los integrantes. Cuando ocurre esto, se dice que estos elementos son totalmente puros, pero cuando existe un integrante distinto es considerado impuro, como cuando una persona quiere separar la clara de la yema de un huevo y no lo consigue, por ende, esta mezcla se encuentra contaminada: "En el intento por ejercer el control por parte de aquellos que poseen el poder y el ojo categórico y que intentan separar todas las cosas impuras para convertirlas en elementos puros, (como la separación de la clara y la yema pertenecientes a un huevo), con el propósito de controlar". ${ }^{10}$

Se estudia la heterosexualidad como una estructura de dominación, un régimen político que a lo largo de la historia ha oprimido; por ende, debería cuestionarse como algo natural y deconstruirse de las categorías binarias existentes para que exista una ruptura total en las lógicas del sometimiento heterosexista. ${ }^{11}$ Es aquí donde se piensa se encuentran en nuestra actual sociedad las personas con distinta orientación sexual, considerados seres humanos impuros, heterogéneos, con la necesidad de otros por cambiarlos, y sometidos para estructuras de dominación heterosexuales. Por esto Gayle Rubin examinaba lo que se nombró como "jerarquía sexual con el objeto de analizar la división entre sexualidades consideradas normalizadas y aquellas consideradas desviadas, reflejando como el límite, la norma, es una cuestión de poder objeto de disputas y resistencias políticas". ${ }^{12}$

Se pretende que los individuos dentro de una comunidad sean homogéneos. Se requiere esto para aplicar el control a todos de la misma forma y cualquier individuo distinto aparece como extraño, inadaptado o como una amenaza para esta agrupación.

9. Corte Constitucional del Ecuador, sentencia n. ${ }^{\circ} 10-18-\mathrm{CN} / 19$, causa n. $^{\circ} 10-18-\mathrm{CN}$ (matrimonio entre personas del mismo sexo).

10. María Lugones, Pureza, impureza y separación (Nueva York: Rowman \& Littlefield Prensa, 2003).

11. Lola Martínez Pozo, "Disidencias sexuales y corporales: Articulaciones, rupturas y mutaciones". Psicoperspectivas. Individuo y sociedad, vol. 17, n. ${ }^{\circ} 1$ (2018), 〈http://dx.doi.org/10.5027/psicoperspectivasvol17-issue1-fulltext-1141〉.

12. Ibíd. 
Enumerando algunos ejemplos, están los negros que fueron tomados como esclavos, las mujeres quienes hasta la actualidad permanecen luchando por derechos no reconocidos; indígenas, judíos y migrantes. Cuando se analiza el matrimonio civil como institución y a las personas con una distinta orientación sexual son tomados como seres fuera de la normalización heterosexual. Los amantes de la pureza consideran, como decía Lugones, que con la opresión se llega al éxito se logra la opresión de estos seres distintos mediante la fragmentación de estos grupos.

Los recientes procesos iniciados por varias parejas homosexuales, movilizaciones o en sí, al continuar adelante en sus trabajos o en cualquier ámbito a pesar de ser señalados por parte de la homogeneidad, son formas de resistencia hacia la normalización, siendo esto una forma de mantenerse firme o de soportar la opresión de la manera en la que fuera; un ejemplo es el cuento "Matronas" de Yolanda Arroyo; en este, las esclavas negras al momento de parir rogaban a la partera igualmente negra que asesinara al bebé con el fin de que no llegue a ser un elemento más de la dominación blanca. Esa, el matar a sus hijos, era su manera de oponerse a lo establecido.

Si las mujeres, los pobres, los no-blancos, los queer, las personas con culturas (cuyas culturas son negadas e invisibilizadas) son considerados impropios de lo público, es porque estamos manchados por la necesidad, la emoción, el cuerpo. Esta mancha está relacionada con la necesidad del sujeto moderno por controlar a través de la unidad, la producción y el mantenimiento de sí mismo como unificado. ${ }^{13}$

Los individuos con distinta orientación sexual distinta a la heteronorma o al binarismo tradicional han sido objeto de dominación, discriminación y exclusión por quienes tienen el poder y aplican el control; para apreciar esto, se ha tomado del Instituto Nacional de Estadística y Censos los resultados que se podrán observar en la página siguiente.

Este estudio es la primera investigación (estudio de caso) sobre condiciones de vida, inclusión social y derechos humanos de la población LGBTI en Ecuador, que fue realizada mediante un muestreo no probabilístico utilizando una metodología conocida como bola de nieve,${ }^{14}$ tomando a 2.805 entrevistados pertenecientes a la población de referencia. Examinando los datos se puede apreciar que esta población es víctima de discriminación, violencia y exclusión; el más alto porcentaje de los dos primeros ocurren en espacios públicos, mientras que el mayor índice de exclusión a personas con distinta

13. Lugones, Pureza, impureza y separación.

14. Esta metodología se basa en que cada persona elige a otras de la población objeto de estudio consiguiendo con esto un acceso más amplio a la información requerida, se la conoce también como una red social, obtenido en 〈https:/www.ecuadorencifras.gob.ec//documentos/web-inec/Estadisticas_Sociales/LGBTI/ Presentacion-LGBTI.pdf〉. 


\section{Experiencias de discriminación en distintos entornos}

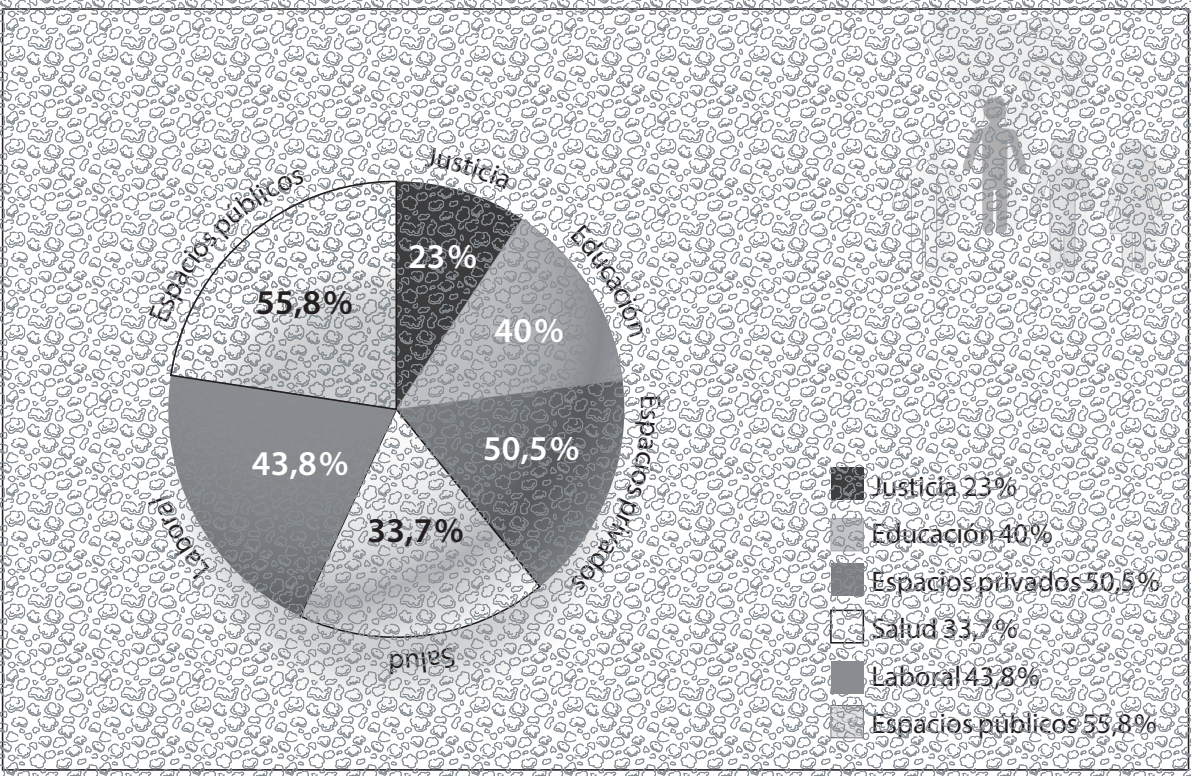

Fuente: Instituto Nacional de Estadística y Censos, Condiciones de vida, inclusión social y derechos humanos de la población LGBTI en Ecuador, accedido 20 de septiembre de 2019, 〈https://www.ecuadorencifras. gob.ec//documentos/web-inec/Estadisticas_Sociales/LGBTI/Presentacion-LGBTI.pdf〉.

\section{Experiencias de violencia en distintos entornos}

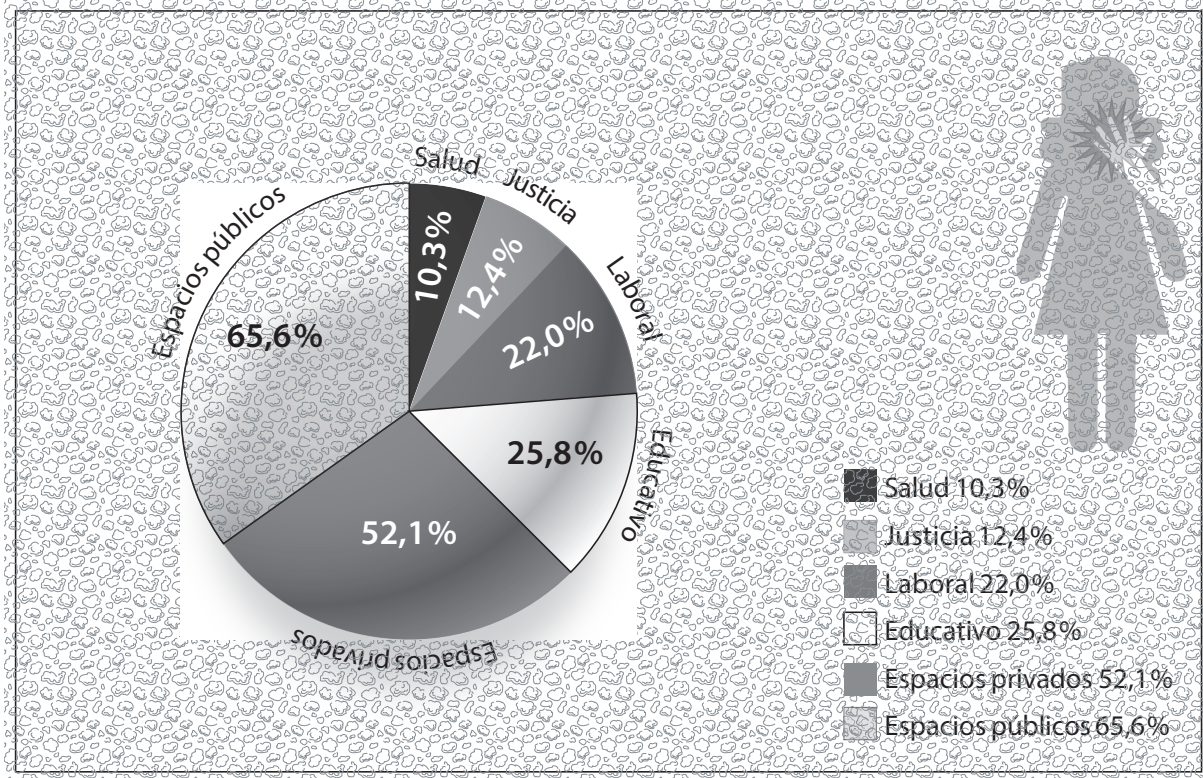

Fuente: Instituto Nacional de Estadística y Censos, Condiciones de vida, inclusión social y derechos humanos de la población LGBTI en Ecuador, accedido 20 de septiembre de 2019, 〈https://www.ecuadorencifras. gob.ec//documentos/web-inec/Estadisticas_Sociales/LGBTI/Presentacion-LGBTI.pdf〉. 


\section{Experiencias de exclusión en distintos entornos}

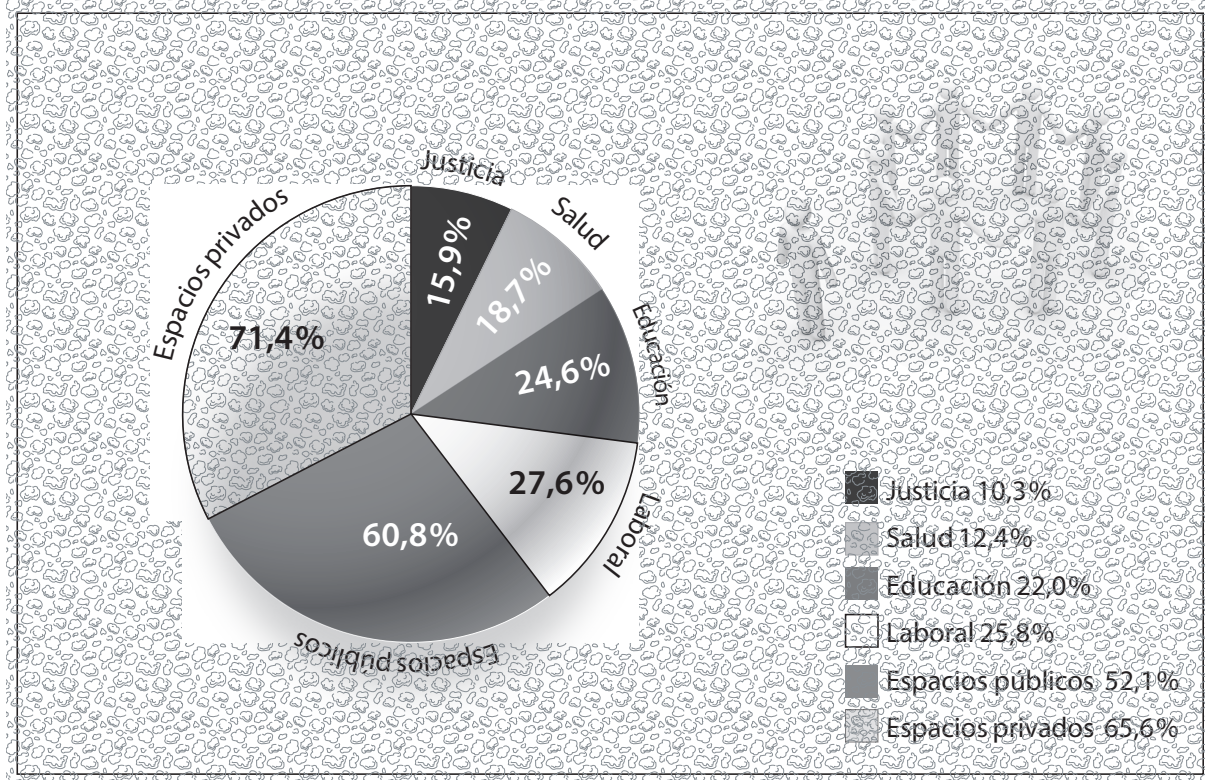

Fuente: Instituto Nacional de Estadística y Censos, Condiciones de vida, inclusión social y derechos humanos de la población LGBTI en Ecuador, accedido 20 de septiembre de 2019, «https://www.ecuadorencifras. gob.ec//documentos/web-inec/Estadisticas_Sociales/LGBTI/Presentacion-LGBTI.pdf».

orientación sexual se da en espacios privados, es decir, dentro del núcleo más cercano, familia y amigos; la sentencia n. ${ }^{\circ} 10-18-\mathrm{CN} / 19$ acerca del matrimonio civil igualitario emitida por la Corte Constitucional actual al respecto afirma:

La discriminación que afecta a las personas LGBT en las sociedades de la región las inserta en un ciclo de exclusión que tiende a culminar en la pobreza por falta de acceso a servicios, oportunidades y prestaciones sociales que en algunos casos inicia desde la temprana edad. Frente a esto la CIDH ha declarado que la discriminación y violencia contra niñas, niños y jóvenes con orientaciones sexuales e identidades de género no normativas empieza en el hogar y en las escuelas, donde la familia, los miembros de la comunidad, profesores/as de las escuelas desaprueban su orientación sexual y/o identidad de género. Las personas LGBT son expulsadas de sus familias y escuelas, y en algunos casos ni siquiera pueden obtener trabajos que pagan el salario mínimo. ${ }^{15}$

Las parejas del mismo sexo excluidas de la institución del matrimonio sufren consecuencias normativas y simbólicas ya que generan efectos degradantes y estigmati-

15. Corte Constitucional del Ecuador, sentencia n. ${ }^{\circ} 10-18-\mathrm{CN} / 19$, causa n. ${ }^{\circ}$ 10-18-CN (matrimonio entre personas del mismo sexo). 
zantes que influyen en sus vidas, situación que es mayormente visible en Estados con una gran desigualdad socioeconómica como el Ecuador; estas personas son expuestas a maltratos y humillaciones, en virtud de que no responden a lo que socialmente se espera de uno y otro sexo. ${ }^{16}$

Ahora bien, volviendo a la sentencia analizada, es muy poco útil buscar tratar a estos seres humanos en iguales circunstancias que a las personas heterosexuales. Esto básicamente fue lo que buscó hacer el tribunal cuando se concluyó que no fueron discriminados en razón de su orientación sexual, ya que no existe otra pareja en las mismas circunstancias a quienes se les ofició un matrimonio civil, produciendo graves consecuencias en el desarrollo de su vida y no pudiendo lograr una vida digna; por ende, la Corte Constitucional ecuatoriana sugiere: "si el legislador ecuatoriano institucionalizara el matrimonio entre personas del mismo sexo fomentaría el ideal constitucional del buen vivir, tanto en su vertiente individual como en la colectiva". ${ }^{17}$

Si realizamos un test podemos darnos cuenta de que este no es criterio suficiente y razonable para hacer una distinción entre personas homosexuales y heterosexuales con relación a la institución del matrimonio civil (el eclesiástico es cuestión de otro tipo de reflexión y análisis), básicamente no pueden realizarlo en razón de su orientación sexual, ya que, si los recurrentes se presentaran cada uno con una mujer y dos testigos cumpliendo todos los requisitos, se procedería como es común a celebrar el contrato civil. Por consiguiente, esta distinción es totalmente discriminatoria a los derechos de los peticionarios. La Corte Interamericana de Derechos Humanos determina que "el alcance del derecho a la no discriminación por orientación sexual no se limita a la condición de homosexual en sí misma, sino que incluye su expresión y las consecuencias necesarias en el proyecto de vida de las personas". ${ }^{18}$

Adicionalmente, la sentencia $n .^{\circ}$ 184-18-SEP-CC, en el caso Satya, indicaba lo siguiente con respecto al derecho a la igualdad y no discriminación:

La dignidad e igualdad deben ser leídas en forma conjunta, pues la plena realización humana depende del respeto, protección, garantía y promoción de los derechos, sin distinciones abusivas o arbitrarias. La construcción de la igualdad sin discriminaciones fortalece además la diversidad de identidades, pueblos y nacionales que conforman el Estado constitucional. ${ }^{19}$

16. Ibíd.

17. Ibíd.

18. Convención Interamericana de Derechos Humanos, encontrado en «http://www.corteidh.or.cr/cf/Jurisprudencia2/ficha_tecnica.cfm?nId_Ficha=196).

19. Corte Constitucional del Ecuador, sentencia n. ${ }^{\circ}$ 184-18-SEP-CC, causa n. ${ }^{\circ}$ 1692-12-EP. 
Esto englobaría el derecho a poder crecer en un ambiente sano, acceder al sistema de educación público o privado, contraer matrimonio, formar una familia, obtener una jubilación, en otras palabras, tener una vida digna. La ampliación de la figura de la unión de hecho fue el primer paso hacia una eficaz protección de derechos. Con anterioridad, en caso de muerte de una de las personas, la pareja sobreviviente no tenía derecho alguno como lo tendría el cónyuge vivo, por lo que fue un progreso en lo que se refiere a reconocimiento de derechos a parejas de este tipo. Sin embargo, este desarrollo positivo de derechos no se debe tomar como una solución para parejas con distinta orientación sexual, ya que, de lo que se puede deducir de la sentencia, el tribunal, al igual que el Registro Civil, indica que pueden inscribir la unión de hecho y que esta figura está destinada para este tipo de parejas, como dando un tipo de alivio para que se la tome como una institución para estas parejas y el matrimonio para heterosexuales. Argumento que vulnera el principio de igualdad y no discriminación; la dignidad y por ende el resto del catálogo de derechos contenidos en la Constitución y en instrumentos internacionales que se desprende de los mismos, ya que las personas heterosexuales tienen la posibilidad de elegir entre el matrimonio civil o la unión de hecho, contrario con lo que ocurre con las parejas no normalizadas.

Han existido cuestionamientos acerca de crear una institución igual al matrimonio, pero con distinto nombre para uniones entre parejas homosexuales; al respecto, la Corte Constitucional ecuatoriana citó a la Suprema Corte de México de la siguiente manera:

inherentemente discriminatorio [...] porque constituir[ía] un régimen de "separados pero iguales". Así como la segregación racial [en Estados Unidos] se fundamentó en la inaceptable idea de la supremacía blanca sobre los afroamericanos, la exclusión de las parejas homosexuales del matrimonio y/o del concubinato, también está basada en los prejuicios que históricamente han existido en contra de los homosexuales. ${ }^{20}$

\section{La Opinión Consultiva OC-24/17 EN EL ORDENAMIENTO JURÍDICO ECUATORIANO}

Acerca de la opinión consultiva en cuestión, la sentencia de la Sala de lo Laboral señala que no es obligatoria, en razón de que no tiene la categoría de tratado o convenio internacional, como se encuentra en el art. 425 de la norma suprema, aunque generalmente es respetado y reconocido por los Estados, es decir, a pesar de que se

20. Corte Constitucional del Ecuador, sentencia n. ${ }^{\circ} 10-18-\mathrm{CN} / 19$, causa n. ${ }^{\circ} 10-18-\mathrm{CN}$ (matrimonio entre personas del mismo sexo). 
reconozca el matrimonio entre parejas del mismo sexo y se proteja los diversos tipos de familia (esto igualmente reconocido en nuestro país), no es vinculante en estricto sentido para el Estado ecuatoriano. Al interpretarse en relación al Principio de Favorabilidad no formaría parte del Bloque de Constitucionalidad, ya que este consiste en la normativa, principios y valores que se encuentran fuera de la Constitución en sí, pero que tiene como función el control de constitucionalidad de normas de menor jerarquía. Esto con relación a que explícitamente, dentro del mencionado cuerpo normativo, está establecido únicamente el matrimonio entre hombre y mujer. La única forma de que este instrumento forme parte del ordenamiento sería cumpliendo el procedimiento establecido, mediante la adecuación interna por medio del órgano legislativo, es decir, la Asamblea Nacional, conforme el art. 84 de la Constitución vigente.

El art. 64 de la Convención Americana de Derechos Humanos establece que los Estados miembros podrán consultar a la Corte acerca de la interpretación de la Convención o de otros tratados concernientes a la protección de derechos humanos en los Estados americanos. Los recurrentes en razón de que para la resolución del caso Satya se tomó en consideración esta opinión, consideraron de igual manera, se podía aplicar para su caso específico. $^{21}$

En Derecho Internacional Público, el país miembro, en este caso, de la Organización de Estados Americanos, por tradición y por el pacta sunt servanda, la respetan y reconocen. Sin embargo, en base a lo alegado por el Tribunal de lo Laboral, el Registro Civil y el delegado de la Procuraduría General del Estado, constituye únicamente un criterio no obligatorio, considerado en otro proceso en virtud de existir un vacío legal, problema que no ocurre en la presente causa por tratarse de normativa expresa.

La actual Constitución es progresista en materia de derechos humanos y tiene como fin el amparo y protección de derechos de las personas y de la naturaleza. Sin embargo, el mencionado tribunal no lo dedujo de esa manera, sino, por el contrario, no aplica de ninguna manera la Opinión Consultiva OC-24/17, vulnerando normas constitucionales. Así lo demuestran los siguientes artículos:

Art. 11.- El ejercicio de los derechos se regirá por los siguientes principios: 7. El reconocimiento de los derechos y garantías establecidos en la Constitución y en los instrumentos internacionales de derechos humanos, no excluirá los demás derechos derivados de la dignidad de las personas, comunidades, pueblos y nacionalidades, que sean necesarios para su pleno desenvolvimiento. ${ }^{22}$

21. Función Judicial, Sala de lo Laboral de la Corte Provincial del Azuay, Proceso n. ${ }^{\circ}$ 01204-2018-03635, 2018.

22. Artículo 11.7, Constitución de la República del Ecuador, Registro Oficial n. ${ }^{\circ}$ 449, 20 de octubre de 2008 (vigente). 
Art. 417.- Los tratados internacionales ratificados por el Ecuador se sujetarán a lo establecido en la Constitución. En el caso de los tratados y otros instrumentos internacionales de derechos humanos se aplicarán los principios pro ser humano, de no restricción de derechos, de aplicabilidad directa y de cláusula abierta establecidos en la Constitución. ${ }^{23}$

Art. 424.- La Constitución es la norma suprema y prevalece sobre cualquier otra del ordenamiento jurídico. Las normas y los actos del poder público deberán mantener conformidad con las disposiciones constitucionales; en caso contrario carecerán de eficacia jurídica. La Constitución y los tratados internacionales de derechos humanos ratificados por el Estado que reconozcan derechos más favorables a los contenidos en la Constitución, prevalecerán sobre cualquier otra norma jurídica o acto del poder público. ${ }^{24}$

Art. 426.- Todas las personas, autoridades e instituciones están sujetas a la Constitución. Las juezas y jueces, autoridades administrativas y servidoras y servidores públicos, aplicarán directamente las normas constitucionales y las previstas en los instrumentos internacionales de derechos humanos siempre que sean más favorables a las establecidas en la Constitución, aunque las partes no las invoquen expresamente. ${ }^{25}$

En los artículos antes descritos los términos instrumentos internacionales son una fuente de derechos junto con la norma suprema. En derecho internacional estos pueden ser de dos clases, los convenios y los demás instrumentos de derechos humanos. La diferencia entre ambos es que el primero necesita la ratificación a través del control de constitucionalidad, aprobación parlamentaria y depósito del mismo; el segundo, requiere únicamente la suscripción. ${ }^{26}$ De esta manera lo ha analizado la Corte Constitucional ecuatoriana en la sentencia n. ${ }^{\circ}$ 11-18-CN/19, de igual forma acerca del matrimonio civil igualitario.

$\mathrm{Si}$, efectivamente, la mencionada opinión consultiva no tiene el rango de tratado o convenio internacional (como lo alegaba el tribunal para su no aplicación), sin embargo, existen normas expresas y supremas que contemplan que dicha opinión se encuentra dentro de estos instrumentos, por lo que los jueces debieron realizar una aplicación a favor de los derechos, primero, de los recurrentes y, segundo, de las personas en general, como lo realizó la jueza de primera instancia. La sentencia Satya cita lo siguiente:

23. Artículo 417, Constitución de la República del Ecuador, Registro Oficial n. ${ }^{\circ}$ 449, 20 de octubre de 2008 (vigente).

24. Artículo 424, Constitución de la República del Ecuador, Registro Oficial n. ${ }^{\circ} 449,20$ de octubre de 2008 (vigente).

25. Artículo 426, Constitución de la República del Ecuador, Registro Oficial n. ${ }^{\circ}$ 449, 20 de octubre de 2008 (vigente).

26. Corte Constitucional del Ecuador, sentencia n. ${ }^{0} 11-18-\mathrm{CN} / 19$, causa n. ${ }^{0} 11-18-\mathrm{CN}$ (matrimonio igualitario). 
La Corte Interamericana en la Opinión Consultiva OC-24/17, instrumento internacional que, por expresa disposición del artículo 424 de la Constitución de la República y por constituir interpretación oficial del órgano interamericano encargado de determinar el sentido y alcance de las disposiciones convencionales relacionadas con la protección de derechos humanos, se entiende adherido al texto constitucional y es de aplicación directa, inmediata y preferente, en tanto su contenido sea más favorable para el efectivo ejercicio y protección de derechos. ${ }^{27}$

La sentencia n. ${ }^{\circ}$ 11-18-CN/19 sobre matrimonio igualitario sobre este tema indica:

Las opiniones consultivas son una interpretación emitidas por un órgano supranacional, en este caso la corte IDH, la competencia de la misma nace de un tratado internacional del que el Ecuador es parte y tiene la obligación de cumplir de buena fe y sin la posibilidad de incumplir el mismo teniendo como justificación la normativa interna; por ende, estos derechos forman parte del sistema jurídico ecuatoriano y por consiguiente del bloque de constitucionalidad, es decir, tenían la misma jerarquía de la Constitución ecuatoriana y son de directa e inmediata aplicación. ${ }^{28}$

Al tener el signatario de un tratado internacional que cumplir con lo que se ha comprometido y adicionalmente tener que hacerlo de buena fe surge lo que se conoce como control de convencionalidad, surgiendo la obligación del Estado de ejecutarla incluidas las interpretaciones, contexto y propósitos en razón del derecho internacional público. La Corte Constitucional afirmó en su sentencia n. ${ }^{\circ}$ 11-18-CN/19 (matrimonio igualitario):

La Corte IDH, en adelante, ha ido precisando las obligaciones que se derivan del control de convencionalidad y que esta Corte Constitucional las adopta: a) el control de constitucionalidad se complementa con el de convencionalidad y hay que hacerlas de oficio; b) el control de convencionalidad lo hacen las autoridades públicas en el marco de sus competencias; c) el control de convencionalidad es de tratados y de las interpretaciones de sus órganos; $\mathrm{y}, \mathrm{d}$ ) el control de convencionalidad también aplica en las opiniones consultivas. ${ }^{29}$

En tal sentido, tanto de acuerdo a los artículos de la actual Constitución como en la sentencia mencionada, la Opinión Consultiva OC-24/17 sin lugar a dudas forma parte del Bloque de Constitucionalidad, ya que como hemos analizado es un instrumento internacional de derechos humanos y, por ende, se lo debe aplicar de manera directa e

27. Corte Constitucional del Ecuador, sentencia n. ${ }^{\circ}$ 184-18-SEP-CC, causa n. ${ }^{\circ}$ 1692-12-EP.

28. Corte Constitucional del Ecuador, sentencia n. ${ }^{\circ} 11-18-\mathrm{CN} / 19$, causa $n .^{\circ} 11-18-\mathrm{CN}$ (matrimonio igualitario).

29. Corte Constitucional del Ecuador, sentencia n. ${ }^{\circ} 11-18-\mathrm{CN} / 19$, causa ${ }^{\circ}{ }^{\circ} 11-18-\mathrm{CN}$ (matrimonio igualitario). 
inmediata sin que se necesite reglamento alguno para su efectivo goce y protección y no existe justificación alguna para su incumplimiento.

El momento en que los recurrentes acudieron al Registro Civil era obligación de esta institución, en virtud de la normativa actual vigente, celebrar el matrimonio civil. Al tener una negativa por parte de estos era deber de los operadores de justicia, es decir, la jueza en primera instancia y de la sala en segunda instancia, garantizar la no vulneración de ningún derecho constitucional de los peticionarios.

\section{CONCLUSIONES}

Las personas con una distinta orientación sexual, en este caso específico los homosexuales, han sido vulneradas y oprimidas, sometidas al control y al dominio de la normalización heterosexual, primero en una especie de ocultamiento, posteriormente convirtiéndolos en delincuentes, y, por último, restringiendo ciertas facultades únicamente para heterosexuales, como el matrimonio civil.

En el caso del Estado ecuatoriano, el matrimonio civil se encuentra regulado entre hombre y mujer. No se han considerado otras formas del mismo, aunque se ha reconocido paradójicamente la diversidad de familias, lo que podría tener respuesta en ideologías particulares.

La sentencia de segunda instancia es un claro menoscabo a derechos humanos de personas con distinta orientación sexual, ya que, como se ha podido analizar en las sentencias de la Corte Constitucional, indicando que el Ecuador es signatario de la Convención sobre Derechos Humanos y, mediante un tratado internacional sin vicio alguno, se obligó soberanamente ante la Corte IDH.

El caso analizado es un claro ejemplo de retroceso en lo referente a derechos humanos. El Tribunal de lo Laboral, Registro Civil y la Procuraduría General del Estado trata a los recurrentes como a personas heterosexuales, no toma en cuenta que son un grupo vulnerable y que su orientación sexual es una categoría protegida en la Constitución ecuatoriana en el artículo 11 número 2; por lo que, se los trata en relación a la igualdad formal y no a la igualdad material. Se volvió sin lugar a dudas a la primera y sin consideración alguna de su calidad.

El Estado ecuatoriano, al ser signatario de la Organización de los Estados Americanos, tal y como se encuentra en la Convención Americana de Derechos Humanos, debe asegurarse de que ninguna norma del ordenamiento jurídico o cualquier otro vulnere derechos humanos; en tal razón es necesario que el inciso segundo del artículo 67 sea reformado, ya que provoca una clara violación al principio de igualdad y no discriminación y, por ende, a la vida digna dentro de la propia Constitución y del que gozan o deberían gozar todas las personas. 
Si observamos el hecho producto del cual se estableció esta vulneración al principio de igualdad y no discriminación, podemos llegar a la conclusión que cualquier distinción entre seres humanos debe realizarse en virtud de un argumento razonable, fundamentado, no arbitrario, precautelando el derecho de las personas que serían objeto de esta diferenciación. En este proceso, en específico, los peticionarios son una pareja homosexual que pudiera ser cualquier otra; la única opción que tienen para poder formar una familia, como es su deseo, y desarrollarse en un ambiente sano, es mediante la figura de la unión de hecho y no, por motivos ya expuestos, mediante la celebración del matrimonio civil, lo cual es totalmente injusto y regresivo en materia constitucional.

La opinión consultiva OC-24/17 tiene dos calidades, la primera de instrumento internacional y la segunda de derechos humanos, como pudimos examinar forma parte en virtud del art. 11.7, 424 y 426 de la Constitución, del ordenamiento jurídico y por tanto todas las instituciones del sector público, así como los particulares y en sí el sector privado debe aplicarlos directa e inmediatamente. En razón de la progresividad y de la cláusula abierta de la Constitución, debía ser considerada, con el fin de asegurar el eficaz cumplimiento de los derechos para las personas, y no basarse solamente en conceptos constitucionales y estrictamente legales del matrimonio como lo es el art. 67 y el Código Civil.

\section{BIBLIOGRAFÍA}

Constitución de la República del Ecuador. Asamblea Nacional, 2008.

Convención Interamericana de Derechos Humanos. Encontrada en 〈http://www.corteidh.or.cr/ cf/Jurisprudencia2/ficha_tecnica.cfm?nId_Ficha=196).

Corte Constitucional del Ecuador. Sentencia 010-14-SEP-CC. Encontrada en 〈http://portal. corteconstitucional.gob.ec:8494/FichaRelatoria.aspx?numdocumento=010-14-SEP-CC .

—. Sentencia 184-18-SEP-CC. Encontrada en 〈http://portal.corteconstitucional.gob.ec:8494/ FichaRelatoria.aspx?numdocumento=184-18-SEP-CC .

—. Sentencia 10-18-CN/19. Encontrada en 〈https://drive.google.com/file/d/14QNINLjZIJkXt epxou1s2uZTUk5Kftyx/view>.

—. Sentencia 11-18-CN/19. Encontrada en «ttps://drive.google.com/file/d/14QNINLjZIJkXt epxou1s2uZTUk5Kftyx/view>.

Corte Interamericana de Derechos Humanos. Cuadernillo de Jurisprudencia de la Corte, $\mathrm{n} .{ }^{\circ}$ 14: Igualdad y No Discriminación, 2017.

Función Judicial, Sala de lo Laboral de la Corte Provincial del Azuay. Proceso n. ${ }^{\circ}$ 01204-201803635, 2018.

Instituto Nacional de Estadística y Censos. Condiciones de vida, inclusión social y derechos humanos de la población LGBTI en Ecuador. Accedido 20 de septiembre de 2019. «https:// 
www.ecuadorencifras.gob.ec//documentos/webinec/Estadisticas_Sociales/LGBTI/Presentacion-LGBTI.pdf〉.

Martínez Pozo, Lola. "Disidencias sexuales y corporales: articulaciones, rupturas y mutaciones”. Psicoperspectivas. Individuo y sociedad. Vol. 17, n. ${ }^{\circ} 1$ (2018). 〈http://dx.doi. org/10.5027/psicoperspectivas-vol17-issue1-fulltext-1141>.

Saba, Roberto. Más allá de la igualdad formal ante la ley: ¿qué les debe el Estado a los grupos desventajados? (Buenos Aires: Siglo XXI, 2006).

Salvioli, Fabián. Un análisis desde el principio pro persona sobre el valor jurídico de las decisiones de la Comisión Interamericana de derechos humanos. Buenos Aires: Ediar, 2003. 